\title{
The cutoff of transient elastography for the evaluation of portal hypertension should be different according to the etiology?
}

\author{
Beom Kyung Kim ${ }^{1,2,3}$ \\ 'Department of Internal Medicine, ${ }^{2}$ Institute of Gastroenterology, Yonsei University College of Medicine, Seoul; ${ }^{3}$ Yonsei Liver Center, \\ Severance Hospital, Seoul, Korea
}

Keywords: Liver stiffness; Portal hypertension; Cirrhosis; Etiology

\section{See Article on Page 197}

Portal hypertension $(\mathrm{PH})$ is a major consequence of liver tissue fibrogenesis ${ }^{1}$ that results in serious complications such as variceal bleeding, ascites, and hepatic encephalopathy among patients with liver cirrhosis. ${ }^{2}$ Hence, $\mathrm{PH}$ is responsible for significant morbidity and mortality, particularly among patients with decompensated cirrhosis. ${ }^{3,4}$ The hepatic venous pressure gradient (HVPG), the gradient between wedged (i.e., balloon-occluded) and free hepatic venous pressure, is considered the reference standard for assessing the degree of $\mathrm{PH}$. Thus, clinically significant $\mathrm{PH}$, usually defined as an HVPG of $\geq 10 \mathrm{mmHg}$, is associated with the formation of esophageal varices and with a poor prognosis. ${ }^{5-8}$ However, the routine assessment of HVPG in the clinical setting is limited by its invasiveness and the need for expertise and specialized equipment such as an angio-intervention unit. Thus, alternative approaches with acceptable diagnostic performance are needed for clinicians to noninvasively assess PH in patients with cirrhosis.
Recently, accumulating evidence has suggested that liver stiffness (LS) assessed using transient elastography (TE) can adequately reflect the findings of HVPG, indicating that it is a useful modality for evaluating $\mathrm{PH}$ and the resultant cirrhotic complications. ${ }^{9-15}$ However, TE is not sufficiently accurate to replace HVPG due to its insufficient sensitivity and specificity. ${ }^{16}$ Furthermore, TE has limitations for clinical application because of the wide range of cutoff values (range, 13.9-21.5 kPa) and variability in performance among studies (area under the receiver operating characteristic curve, 0.76-0.85). ${ }^{10,17,18}$ Recently, Ryu et al. ${ }^{19}$ evaluated the correlation between $L S$, LS to platelet ratio (LPR), LS-spleen diameter-to-platelet ratio score (LSPS), and HVPG according to the etiology of cirrhosis (alcoholic cirrhosis vs. viral cirrhosis).

According to the Baveno VI recommendations, an LS cutoff of $21 \mathrm{kPa}$ can be used to confirm the presence of clinically significant $\mathrm{PH}^{11,20}$ However, most evidence to support this recommendation was based on studies that had recruited patients with viral cirrhosis. Ryu et al. ${ }^{19}$ reported a higher LS value in patients with alcoholic cirrhosis than in those with viral cirrhosis (43.5. vs. $32.0 \mathrm{kPa}$,

\section{Abbreviations:}

HVPG, hepatic venous pressure gradient; LPR, liver stiffness to platelet ratio; LS, liver stiffness; LSPS, liver stiffness-spleen diameter-to-platelet ratio score; $\mathrm{PH}$, portal hypertension; PPV, positive predictive value; TE, transient elastography

\section{Corresponding author : Beom Kyung Kim}

Department of Internal Medicine, Yonsei University College of Medicine, 50 Yonsei-ro, Seodaemun-gu, Seoul 03722, Korea

Tel: +82-2-2228-1930, Fax: +82-2-393-6884

E-mail: beomkkim@yuhs.ac

https://orcid.org/0000-0002-5363-2496 
$P<0.001)$, whereas there were no significant differences in the LPR or LSPS between the two groups. Ryu et al. ${ }^{19}$ also suggested an LS cutoff value of $32.2 \mathrm{kPa}$ with a positive predictive value (PPV) of $94.5 \%$ to predict an HVPG $\geq 10 \mathrm{mmHg}$ and an LS cutoff value of $36.6 \mathrm{kPa}$ with a PPV of $91.0 \%$ to predict an HVPG $>12 \mathrm{mmHg}$. However, there are several considerations when interpreting these results.

First, while the hypothesis that the higher the LS value, the worse the prognosis might be generally reasonable, the association between the $L S$ value and fibrotic burden might be non-linear. Furthermore, the correlation between the $L S$ value and the risk of $\mathrm{PH}$-related complications might be even more nonlinear, given that $\mathrm{LS}$ is primarily a fibrosis-marker and not a hemodynamic parameter. In a similar context, the measurement of spleen stiffness by ultrasound seemed to at least partially overcome the limitations associated with the $\mathrm{LS}$ value in the evaluation of $\mathrm{PH}^{21}$ In contrast, Ryu et al. ${ }^{19}$ showed that the addition of spleen diameter and/or platelet count did not improve the predictive performance compared to that of the LS value alone. Thus, further studies to evaluate the role of other ancillary methods based on laboratory, ultrasonography, and other markers are required. Second, the prognostic performance of alcoholic cirrhosis-specific LS cutoffs should be validated in further studies in which the cumulative risk of PH-related complications, such as variceal hemorrhage, hepatorenal syndrome, hepatic encephalopathy, and hospital admission for other PH-related complications, should be assessed using longitudinal follow-up. Lastly, Ryu et al. ${ }^{19}$ suggested several hypotheses explaining their observation: the difference in the spatial distribution of fibrosis, with perisinusoidal fibrosis being more frequent, and concomitant necro-inflammation with steatosis in alcoholic cirrhosis. However, the exact mechanism underlying the increase in LS, the degree of increment in the LS value, and the way to adjust for such microscopic milieus in alcoholic cirrhosis remain to be determined.

In conclusion, a relatively higher $L S$ value should be applied to predict clinically significant PH in patients with alcoholic cirrhosis than in patients with viral cirrhosis. However, since the severity of $\mathrm{PH}$ is more dependent on the amount of portal blood inflow and peripheral hemodynamic changes than on the stiffness of the hepatic parenchyma, further studies on ways to assess PH non-invasively are required.

\section{Conflicts of Interest}

The author has no conflicts to disclose.

\section{REFERENCES}

1. Kim MY, Cho MY, Baik SK, Park HJ, Jeon HK, Im CK, et al. Histological subclassification of cirrhosis using the Laennec fibrosis scoring system correlates with clinical stage and grade of portal hypertension. J Hepatol 2011;55:1004-1009.

2. Zhao D, Zhang G, Wang M, Zhang C, Li J. Portal pressure gradient and serum albumin: a simple combined parameter associated with the appearance of ascites in decompensated cirrhosis treated with transjugular intrahepatic portosystemic shunt. Clin Mol Hepatol 2019;25:210-217.

3. Lesmana CRA, Raharjo M, Gani RA. Managing liver cirrhotic complications: overview of esophageal and gastric varices. Clin Mol Hepatol 2020;26:444-460.

4. Seo YS. Prevention and management of gastroesophageal varices. Clin Mol Hepatol 2018;24:20-42.

5. Baik SK. Haemodynamic evaluation by Doppler ultrasonography in patients with portal hypertension: a review. Liver Int 2010;30:14031413.

6. Kim MY, Suk KT, Baik SK, Kim HA, Kim YJ, Cha SH, et al. Hepatic vein arrival time as assessed by contrast-enhanced ultrasonography is useful for the assessment of portal hypertension in compensated cirrhosis. Hepatology 2012;56:1053-1062.

7. Kim MY, Jeong WK, Baik SK. Invasive and non-invasive diagnosis of cirrhosis and portal hypertension. World J Gastroenterol 2014;20:4300-4315.

8. Korean Association for the Study of the Liver (KASL). KASL clinical practice guidelines for liver cirrhosis: varices, hepatic encephalopathy, and related complications. Clin Mol Hepatol 2020;26:83-127.

9. Vizzutti F, Arena U, Romanelli RG, Rega L, Foschi M, Colagrande S, et al. Liver stiffness measurement predicts severe portal hypertension in patients with HCV-related cirrhosis. Hepatology 2007;45: 1290-1297.

10. Lemoine M, Katsahian S, Ziol M, Nahon P, Ganne-Carrie N, Kazemi $F$, et al. Liver stiffness measurement as a predictive tool of clinically significant portal hypertension in patients with compensated hepatitis C virus or alcohol-related cirrhosis. Aliment Pharmacol Ther 2008:28:1102-1110.

11. Bureau C, Metivier S, Peron JM, Selves J, Robic MA, Gourraud PA, et al. Transient elastography accurately predicts presence of significant portal hypertension in patients with chronic liver disease. Aliment Pharmacol Ther 2008;27:1261-1268.

12. Sánchez-Conde $M$, Miralles $P$, Bellón JM, Rincón $D$, Ramírez $M$, Gutiérrez I, et al. Use of transient elastography $\left(\right.$ FibroScan $\left.{ }^{\circledR}\right)$ for the noninvasive assessment of portal hypertension in HIV/HCV-coinfected patients. J Viral Hepat 2011;18:685-691.

13. Carrión JA, Navasa M, Bosch J, Bruguera M, Gilabert R, Forns X. Transient elastography for diagnosis of advanced fibrosis and portal 
hypertension in patients with hepatitis $C$ recurrence after liver transplantation. Liver Transpl 2006;12:1791-1798.

14. Reiberger T, Ferlitsch A, Payer BA, Pinter M, Schwabl P, Stift J, et al. Noninvasive screening for liver fibrosis and portal hypertension by transient elastography--a large single center experience. Wien Klin Wochenschr 2012;124:395-402.

15. Berzigotti A, Seijo S, Arena U, Abraldes JG, Vizzutti F, García-Pagán $J C$, et al. Elastography, spleen size, and platelet count identify portal hypertension in patients with compensated cirrhosis. Gastroenterology 2013;144:102-111.e1.

16. Kim BK. Transient elastography can be integrated into routine clinical practice for the evaluation of portal hypertension? Clin Mol Hepatol 2017;23:27-30.

17. Castéra L, Le Bail B, Roudot-Thoraval F, Bernard PH, Foucher J, Merrouche $W$, et al. Early detection in routine clinical practice of cirrhosis and oesophageal varices in chronic hepatitis C: comparison of transient elastography (FibroScan) with standard laboratory tests and non-invasive scores. J Hepatol 2009;50:59-68.

18. Kazemi F, Kettaneh A, N'kontchou G, Pinto E, Ganne-Carrie N, Trinchet JC, et al. Liver stiffness measurement selects patients with cirrhosis at risk of bearing large oesophageal varices. J Hepatol 2006;45:230-235.

19. Ryu SR, Yoo JJ, Kang SH, Jeong SW, Kim MY, Cho YK, et al. The cutoff value of transient elastography to the value of hepatic venous pressure gradient in alcoholic cirrhosis. Clin Mol Hepatol 2021;27: 197-206.

20. Berzigotti A. Non-invasive evaluation of portal hypertension using ultrasound elastography. J Hepatol 2017;67:399-411.

21. Ma $X$, Wang $L$, Wu $H$, Feng $Y, \operatorname{Han} X, B u H$, et al. Spleen stiffness is superior to liver stiffness for predicting esophageal varices in chronic liver disease: a meta-analysis. PLoS One 2016;11:e0165786. 